\title{
11 \\ IS outsourcing by public sector organisations
}

\author{
L.A. de Looff \\ Delft University of Technology, Department of Information Systems \\ P.O box 356, 2600 AJ Delft, The Netherlands, tel. +31152785827 , \\ fax +31 1527866 32, L.A.deLooff@twi.tudelft.nl
}

\begin{abstract}
IS outsourcing is an innovative organisational tool for IS management in both private and public sector organisations. Following the privatisation trend in the late 1980s, a number of government IS departments were privatised. It is now realised that total privatisation is not always sensible, and less rigorous forms of privatisation are proposed. Case studies of IS outsourcing in a number of (former) public sector organisations have revealed that public sector information systems are often very critical, complex and volatile, due to the information intensity of the processes and the nature of political decision making. This makes outsourcing less attractive. Outsourcing was sometimes chosen to circumvent inflexibilities in the public sector accounting system and compensation rules. These reasons for outsourcing have recently been alleviated.
\end{abstract}

Keywords

IS management, IS outsourcing, public sector, privatisation

\section{INTRODUCTION}

Outsourcing is an innovative organisational tool for information systems (IS) management. Many public sector organisations and private sector corporations expect to improve their IS function by commissioning part or all of their IS activities and resources to external IS suppliers. New information technologies (IT) provide many opportunities for organisations to improve their performance, and even to offer products and services that were not possible before. The question of who is to provide IT applications is therefore crucial if an organisation wants to take advantage of these new developments. 
Much has been written on IS outsourcing and there have been a number of research projects on this subject (Aubert, Rivard and Patry, 1993; Lacity and Hirschheim, 1993; Loh and Venkatraman, 1992; Willcocks and Fitzgerald, 1993). None of these research projects was aimed specifically at IS outsourcing by public sector organisations, even though it is estimated that in the Netherlands, for example, the public sector accounts for a $30 \%$ share of the total IS spending.

\section{RESEARCH DESIGN}

Following a pilot study and a literature review, longitudinal and retrospective case study research was conducted into the actual consequences of IS outsourcing. A total of 23 outsourcing decisions were investigated in six Dutch (former) public sector organisations (see table 1). The cases were investigated using semi-structured interviews and document analysis. The results of the case studies are described in De Looff (1995). A decision model was developed, to support those who are involved in IS outsourcing decision making processes. This model was based on the results of these case studies, and on established organisational theories (De Looff, 1996). In this paper, I focus on the results that are specific to the public sector.

Table 1 Case organisations.

\begin{tabular}{|c|c|}
\hline Name & Description \\
\hline CBS & $\begin{array}{l}\text { The Dutch Central Bureau of Statistics, an independent government agency } \\
\text { providing social and economic statistics. }\end{array}$ \\
\hline DSM & $\begin{array}{l}\text { A multi-national company producing chemical products, originated from the } \\
\text { former Dutch State Mines, that were privatised in the } 1960 \mathrm{~s} \text {. }\end{array}$ \\
\hline Eindhoven & Municipality of Eindhoven. \\
\hline NS & $\begin{array}{l}\text { The Dutch Railways corporation, privatised in } 1995 \text {, but still owned by the } \\
\text { State. }\end{array}$ \\
\hline RWS & Directorate General of Public Works and Water Management. \\
\hline SZW & Ministry of Social Affairs and Employment. \\
\hline
\end{tabular}

\section{RESEARCH RESULTS}

\subsection{Public sector goals}

The public sector is distinguished from the private sector by the fact that making profit and maximising shareholders value is not the main objective of public sector organisations, and that the continuity of public sector organisations does not depend upon outperforming competitors.

The existence and continuity of most public sector organisations is however not self-evident. Though they do not depend on profit or shareholder value for their survival, public sector 
organisations can be reorganised, reduced or even discontinued by higher authorities if their legitimacy or necessity is no longer valid, or if their performance has become unacceptable. Public sector organisations therefore also face a strong pressure to minimise their costs and to maximise the quality of their services.

Additionally, public sector organisations have to meet demands that most private corporations do not face. Public administration involves political and legal factors that have a value-laden component. Public bodies have as an objective the performance of a socially desirable function, which is not a means to generate income, but an end in itself. A citizen's legal security and equality of rights must be guaranteed.

IS outsourcing decisions by public sector organisations are therefore not based upon the consequences for the organisation's competitive position, but upon the effects on the cost and the quality of their services, and on achieving the political objectives and strategies.

\subsection{Privatisation}

Outsourcing by public sector organisations to private suppliers is often called privatisation. This is more fundamental than outsourcing by private corporations, as it implies transferring activities and resources from the public sector to the private sector.

Privatisation is an issue of considerable political and ideological debate. In the 1980s there was a strong trend towards privatisation, to reduce government involvement and to decrease the public sector in favour of free market enterprises. The UK Prime Minister Margaret Thatcher and the US President Ronald Reagan were strong proponents of privatisation. In the Netherlands, the second Cabinet Lubbers followed this trend and privatised a number of public bodies. The privatisation trend was based upon implicit ideological assumptions that markets are inherently more efficient and that decreasing the staffing levels of government organisations would lead to a cheaper and more flexible public sector. Dutch government officials were expected to follow the trend and look for ways to reduce the staffing levels in the public sector; the IS function was an obvious candidate for privatisation, as it was considered to be a support function and not a core activity. A number of Dutch government IS departments were privatised for this reason, some regardless of the possible consequences.

A factor that contributed to the privatisation trend was that the Dutch public sector accounting system differs from what is common in the private sector. It is very attractive to public sector organisations to sell IT assets, as public sector accounting systems prescribe that assets are depreciated in the year they are bought, and have no balance sheet value when they are sold. A strict division between budgets for personnel expenses and for material expenses impeded rational evaluation of the costs of hiring internal personnel versus contracting personnel from external IS suppliers. In some of the cases investigated, the personnel budget was not sufficient to recruit employees, but the material budget allowed the hiring of external IS staff at considerably higher costs, sometimes for several years. In 1992 the strict division between budgets for personnel expenses and for material expenses was removed, and the restrictions on transferring budgets from one year to another were alleviated.

Value Added Tax (VAT) has made outsourcing less attractive to public sector organisations. In the Netherlands, suppliers have to charge $17.5 \%$ VAT on their tariffs, and public sector organisations were not compensated for these extra costs. Currently, the Dutch Ministry of 
Finance compensates public sector organisations for VAT paid in the first few years after a privatisation.

Today it has been realised that the assumptions made about the privatisation trend are not always valid and that privatisation should not be an end in itself. The Dutch Public Accounts Committee, the Algemene Rekenkamer, has criticised several privatisations, including the privatisation of a large government data centre. A government commission, the commissieSint, concluded that pure privatisation, transferring all activities, staff and resources to private corporations, is often not the best option. The commission has proposed the use of less rigorous forms of privatisation and a search for other ways of increasing the flexibility and independency of government organisations. Budgeting and accounting rules have been changed, to allow for trade-offs between personnel and material expenses and for making reservations and depreciations.

\subsection{Characteristics of public sector processes}

The primary processes of most public sector organisations are very information intensive or contain information processing only. Handling requests for social security benefits, maintaining the land registry, and even political decision making, are essentially information processes. All of the six organisations investigated have highly information intensive primary processes. NS and RWS have physical primary processes, but the planning and controlling of these processes is very information intensive. The processes of the CBS consist of collecting and disseminating social and economic information. Public sector organisations are therefore strongly dependent upon their information systems.

The primary processes are almost always unique and are not found in the private sector. Ready-made software packages are not available for most public sector processes and IS suppliers can not use experience and knowledge from other client organisations when they work for public sector organisations, which makes outsourcing less favourable.

The complexity of information systems in the public sector is often very high, mainly because of the complexity of the legislation that underlies the organisations' processes. There are many stakeholders in the policies of public bodies, who may have very different, conflicting and morally justifiable perspectives. Political decision makers give more consideration to fairness and justifiableness than to the practicability of their decisions and the consequences for the information systems. Information systems need to be changed frequently, because of the large number of reorganisations and changes in legislation that public sector organisations face. Most changes have to be implemented instantaneously, sometimes retrospectively. Flexibility and a thorough knowledge of the processes are needed, thus some organisations retain an internal IS department.

\subsection{Cooperation between public sector organisations}

Most primary processes in the public sector are unique; however they are often performed repetitively by a number of similar public sector organisations. Social security benefits are for example provided by all municipalities, and all hospitals have similar information needs, as do schools and environmental inspection units. Secondary processes, such as human resources management and book keeping, are similar across ministries, provinces and municipalities. 
Different processes sometimes need similar information: municipal social security departments and land registry departments both need information on inhabitants. Many public sector organisations could therefore benefit from using the same information systems or information and achieve considerable economies of scale. Cooperation can be more easily achieved in the public sector than in the private sector, as public sector organisations do not compete.

Surprisingly, very few examples of this cooperation were found, and many projects that were outsourced by more than one client organisation did not succeed. Attempts by ministries to develop joint information systems for financial management, human resources management and measurement of air pollution failed or led to only one or a few ministries adopting the system. One of the few successful examples was the cooperation by several ministries in buying and adapting a library management system. There is also a common pay roll system that is used for paying the salaries of all civil servants and all teachers. The system is operated by the former Dutch State Computer Centre, that has become an independent agency.

In the 1970s, regional IS centres were created to serve municipalities and other public sector organisations in their region. The IS departments of the three largest Dutch municipalities are the only regional centres that still exist and also serve smaller municipalities in their region. The regional centre that originated from the IS department of Eindhoven is very successful, despite many problems in the initial phase. They sell software packages for various functions to over a hundred municipalities and other public sector organisations and operate these packages for a few dozen of their clients.

Interviewees explained this lack of cooperation by the fact that the Dutch public sector is highly decentralised and organisations operate autonomously, especially with regard to support functions. Central government has decentralised many responsibilities to the provinces and municipalities, and within ministries, many tasks are decentralised to directorates. The Dutch Ministry of Internal Affairs has a coordinating role in central government's IS management, but no single ministry or government organisation has the authority to enforce cooperation.

\subsection{Personnel issues}

Public sector organisations were not always attractive to IS specialists; the compensation rules did not offer many possibilities for paying personnel according to their market value and for differentiating rewards based on performance, which makes it difficult to recruit and retain good IS staff. The possibilities for differences in payment based on market value and performance are improving.

Internal IS staff of public sector organisations have often objected to being outsourced, because they would cease to be civil servants. Employees have sometimes chosen to be civil servants for ideological reasons. In the Netherlands, there are significant differences in legal and employment conditions between the public and private sector.

\section{CONCLUSIONS}

IS outsourcing by public sector organisations was dominated by the privatisation trend in the 1980s; currently, a more differentiated approach is taken.

Although public sector organisations do not compete with each other sensus strictus, it is necessary to remain efficient and relevant to prevent reorganisation or abolishment of their 
functions. Public sector information systems are very critical, complex and volatile, due to the information intensity of the processes and the nature of political decision making. This makes outsourcing less attractive.

Outsourcing was sometimes chosen to circumvent inflexibilities in the public sector accounting system or because the compensation rules impeded retaining qualified IS staff. These reasons for outsourcing have recently been alleviated. Public sector organisations can take IS outsourcing decisions based on relevant criteria.

\section{REFERENCES}

Aubert, B.A., Rivard, S., Patry, M., (1993) A Transaction Costs Approach to Outsourcing: Some Empirical Evidence. In Gallupe, B. and Todd, P. (eds.), Proceedings of the ASAC IS Division, 14, 164-175.

Lacity, M.C. and R. Hirschheim (1993) Information Systems Outsourcing; Myths, Metaphors and Realities. Wiley, Chichester, England.

Loh, L. and Venkatraman, N. (1992) Determinants of Information Technology Outsourcing: A Cross-Sectional Analysis. Journal of Management Information Systems, 9, 1, 7-24. Looff, L.A. de (1995) Information Systems Outsourcing Decision Making; A Framework, Organisational Theories and Case Studies. Journal of Information Technology, Theme Issue Information Technology Outsourcing: Theory and Practice, 10, 281-297.

Looff, L.A. de (1996) Information Systems Outsourcing: Innovative Concept for Leaner Information Systems Management? in Proceedings of the 1996 IRMA International Conference, Washington D.C.

Willcocks, L. and G. Fitzgerald (1993) Market as opportunity? Case studies in outsourcing information technology and services. Journal of Strategic Information Systems, 2, 3, 223 242.

\section{BIOGRAPHY}

Leon de Looff is a $\mathrm{PhD}$ student at Delft University of Technology and has a degree in Information Systems (Msc). He lectures in courses on Information Economics and on Information Management. His research interests include organisational and economic aspects of information management. He took part in the Ernst \& Young/ICIS Doctoral Consortium 1994. He published in the Journal of Information Technology and presented at international conferences. 